\title{
Assess the Pre Test Knowledge and Practice of Post-Operative Exercises among Abdominal Surgery Patients Before Video Assisted Teaching
}

\author{
Article by Chakrapani Cheekavolu ${ }^{1}$, Vinod kumar Gurram² ${ }^{2}$, P.Leela ${ }^{3}$, Jagan Nadipelly ${ }^{4}$, G. \\ Obulesu $^{5}$ \\ ${ }^{1}$ Assistant Professor, Department of Pharmacology, Kerala Medical College Hospital, Mangode, \\ Palakkad, Kerala, India \\ ${ }^{2}$ Assitant Professor, Department of Anatomy, Kerala Medical College Hospital, Mangode, \\ Palakkad, Kerala, India \\ ${ }^{3} P G$ student, Department of Bio chemistry, SVIMS, Tirupati. Andhra Pradesh, India. \\ ${ }^{4}$ Faculty of Medicine - Pharmacology, Texila American University, Georgetown, Guyana, South \\ America \\ ${ }^{5}$ Assitant Professor, Department of Microbiology, Kerala Medical College Hospital, Mangode, \\ Palakkad, Kerala, India \\ E-mail: chakri14783@gmail.com ${ }^{1}$
}

\begin{abstract}
Background: A study to determine the effectiveness of video assisted teaching in knowledge and practice on post-operative exercises among abdominal surgery patients in selected hospitals at Kerala.

Methodology: A pre experimental research with group pre-test and post-test design and chosen 40 patients was chosen to assess the effectiveness of video assisted teaching programme on post-operative exercises among abdominal surgery patients in tertiary care hospital in Kerala. The study was conducted in tertiary care hospital after obtained the ethical committee approval during the period of July to Dec 2017.

Results: The pre-test knowledge, out of 40 patients all of them 40 (100\%) had inadequate knowledge on post-operative exercises. In post-test knowledge, out of 40 patients one (2.5\%) of them had moderately adequate knowledge, 39 (97.5\%) of them had adequate knowledge and none of them had inadequate knowledge in post-test on post-operative exercises.

Conclusion: The pre-test knowledge had inadequate knowledge on post-operative exercises among abdominal surgery patients in tertiary care hospital in Kerala.
\end{abstract}

Keywords: knowledge and practice, post-operative exercises, abdominal surgery.

\section{Introduction}

Surgery is the art and science of treating diseases, injuries and deformities by operation and instrumentation". Surgery may be performed for the purpose of diagnosis, cure, palliation, cosmetic improvement and prevention. Surgery may be elective in which it is carefully planned and anticipated. The need for surgery may sometimes arise with sudden and unanticipated surgery and is called emergency surgery. The term abdominal surgery broadly covers surgical procedures that involve opening the abdomen. Exercise is important to keep both your body and mind "in shape". Physical exercise is important for maintaining physical fitness and can contribute positively for maintaining a healthy weight, building and maintaining healthy bone density, muscle strength, and joint mobility, promoting physiological well-being, reducing surgical risks, and strengthening the immune system.

Exercising plays an important role in regaining function and strength after undergoing an operation. The goal of post-operative care is to prevent complications such as infection, to promote healing of the surgical incision, and to return the patient to a state of health. Particular patient groups susceptible to fluid or electrolyte disturbances include the elderly, those with pre-existing 
DOI: $10.21522 /$ TIJBMS.2016.02.02.Art008

ISSN: 2519-500X

cardiovascular/cerebrovascular/renal disease and patients who have suffered a peri-operative myocardial ischemic event [1]. In cases of common conditions can affect peri-operative care include ischemic heart disease, congestive cardiac failure, chronic respiratory disease, diabetes mellitus and liver or renal dysfunction [2]. Hypotension is also common post-operatively and has been defined as a systolic blood pressure below $90 \mathrm{mmHg}$ [3]. Causes include hypovolemic due to bleeding or dehydration, or drug therapy. These variables should be measured multiple times during the day, depending on the type of surgery involved. Other examples of monitoring include ECGs, arterial blood gas analysis (ABGs) and central venous pressure (CVP) monitoring [4]. In addition, assessment of drainage and bleeding should also be performed routinely [5].

Having surgery is a major event in any person's life. Some of the patient may respond with expression of helplessness, security and isolation due to discomfort, pain and fear of breaking stitches. These feeling can be minimized with pre-operative teaching about postoperative practice related to activities, nutrition, medication and ambulation. [6]

A study was conducted regarding chest physiotherapy during immediate post-operative period among patients undergoing abdominal surgery. Chest physiotherapy during immediate post-operative period following laparotomy was effective for improving oxygen haemoglobin saturation without increased abdominal pain. Breathing exercises could be adopted post anaesthesia care units with benefits for patients. [7]. the present assessment to determine the effectiveness of video assisted teaching in knowledge and practice on post-operative exercises among abdominal surgery patients in selected hospitals at Kerala.

\section{Methodology}

\section{Research design}

A pre experimental research with group pre-test and post-test design and chosen 40 patients was chosen to assess the effectiveness of video assisted teaching programme on post-operative exercises among abdominal surgery patients in tertiary care hospital in Kerala. The study was conducted in tertiary care hospital after obtained the ethical committee approval during the period of July to Dec 2017. It is a 250 bedded multi-speciality hospital and conducted study in general surgery department.

\section{Inclusion criteria}

Who are in age group between 20-50 years?

Who undergoing abdomen surgery for first time?

Who undergoing abdomen surgery through open laparotomy?

Who are willing to participate?

Who are planning for surgery electively?

\section{Exclusion criteria}

Who are undergoing emergency surgery?

Who are affected with sensory and motor disabled persons? 


\section{Results}

Table 1. Distribution of demographic variables among abdominal surgery patients $(n=40)$

\begin{tabular}{|c|c|c|}
\hline \multirow[t]{2}{*}{ Demographic Variables } & \multicolumn{2}{|c|}{ Abdominal Patients } \\
\hline & Frequency & Percentage (\%) \\
\hline $\begin{array}{l}\text { 1. Age (in years) } \\
\text { a. } 20-30 \\
\text { b. } 31-40 \\
\text { c. } 41-50\end{array}$ & $\begin{array}{l}9 \\
17 \\
14\end{array}$ & $\begin{array}{l}22.5 \\
42.5 \\
35.0\end{array}$ \\
\hline $\begin{array}{l}\text { 2. Gender } \\
\text { a. Male } \\
\text { b. Female }\end{array}$ & $\begin{array}{l}25 \\
15\end{array}$ & $\begin{array}{l}62.5 \\
37.5\end{array}$ \\
\hline $\begin{array}{l}\text { 3. Educational Qualification } \\
\text { a. Non formal education } \\
\text { b. Primary } \\
\text { c. Secondary } \\
\text { d. Higher Secondary } \\
\text { e. Graduate }\end{array}$ & $\begin{array}{l}0 \\
2 \\
12 \\
17 \\
9\end{array}$ & $\begin{array}{l}0.0 \\
5.0 \\
30.0 \\
42.5 \\
22.5\end{array}$ \\
\hline $\begin{array}{l}\text { 4. Occupation } \\
\text { a. Farmer } \\
\text { b. Driver } \\
\text { c. Worker in a company } \\
\text { d. Student } \\
\text { e. House wife }\end{array}$ & $\begin{array}{l}4 \\
8 \\
11 \\
4 \\
13\end{array}$ & $\begin{array}{l}10.0 \\
20.0 \\
27.5 \\
10.0 \\
32.5\end{array}$ \\
\hline $\begin{array}{l}\text { 5. Monthly Income } \\
\text { a. Less than Rs. } 10,000 \\
\text { b. Rs. } 10,000-15,000 \\
\text { c. Rs. } 15,001-20,000 \\
\text { d. Above Rs. } 20,001\end{array}$ & $\begin{array}{l}4 \\
13 \\
18 \\
5\end{array}$ & $\begin{array}{l}10.0 \\
32.5 \\
45.0 \\
12.5\end{array}$ \\
\hline $\begin{array}{l}\text { 6. Family Type } \\
\text { a. Joint } \\
\text { b. Nuclear }\end{array}$ & $\begin{array}{l}29 \\
11\end{array}$ & $\begin{array}{l}72.5 \\
27.5\end{array}$ \\
\hline $\begin{array}{l}\text { 7. Personal Habits } \\
\text { a. Smoking } \\
\text { b. Tobacco and betel leaves } \\
\text { c. Alcohol } \\
\text { d. Nil }\end{array}$ & $\begin{array}{l}8 \\
1 \\
6 \\
25\end{array}$ & $\begin{array}{l}20.0 \\
2.5 \\
15.0 \\
62.5\end{array}$ \\
\hline $\begin{array}{l}\text { 8. Chronic Diseases } \\
\text { a. Diabetes Mellitus } \\
\text { b. Hypertension } \\
\text { c. Asthma } \\
\text { d. Nil }\end{array}$ & $\begin{array}{l}5 \\
4 \\
3 \\
28\end{array}$ & $\begin{array}{l}12.5 \\
10.0 \\
7.5 \\
70.0\end{array}$ \\
\hline
\end{tabular}


DOI: $10.21522 /$ TIJBMS.2016.02.02.Art008

ISSN: $2519-500 \mathrm{X}$

Table 2. Distribution of level of knowledge on post-operative exercises in pre-test among abdominal surgery patients $(n=40)$

\begin{tabular}{|l|l|l|}
\hline Level of Knowledge & Frequency & Percentage \\
\hline Inadequate Knowledge & 40 & 100.0 \\
\hline Moderate Knowledge & - & - \\
\hline Adequate Knowledge & - & - \\
\hline Total & 100.0 & 100.0 \\
\hline
\end{tabular}

Table 3. Distribution of level of knowledge on post-operative exercises in post-test among abdominal surgery patients $(n=40)$

\begin{tabular}{|l|l|l|}
\hline Level of Knowledge & Frequency & Percentage \\
\hline Inadequate Knowledge & 0 & 0.0 \\
\hline Moderate Knowledge & 1 & 2.5 \\
\hline Adequate Knowledge & 39 & 97.5 \\
\hline Total & 100.0 & 100.0 \\
\hline
\end{tabular}

Table 4. Mean and standard deviation for knowledge on post-operative exercises in pre-test and post-test $(n=40)$

\begin{tabular}{|l|l|l|}
\hline $\begin{array}{l}\text { Knowledge on post-operative } \\
\text { exercises }\end{array}$ & Pretest & Post test \\
\hline Mean & 4.55 & 18.00 \\
\hline Standard deviation & 1.39 & 1.13 \\
\hline
\end{tabular}

Distribution of samples in age 20-30years were 9 (22.5\%), 17(42.5\%) were in age 31-40 years and 14 (35\%) were in age41-50 years. Distribution of samples with gender were male $25(62.5 \%)$ and female $15(37.5 \%)$. According to their educational qualification $9(22.5 \%)$ were graduates, $17(42.5 \%)$ were higher secondary, $2(5 \%)$ were primary education (Table 1$)$.

Distribution of samples with their occupation as $4(10 \%)$ were farmers, $8(20 \%)$ were drivers, $11(27.5 \%)$ were worker in a company, students were $4(10 \%)$ and 13(32.5\%) were housewife. Distribution regarding their monthly income $4(10 \%)$ was less than $10,000 /$ month, $13(32.5 \%)$ were $10,000-15,000$ rupees/month, $18(45 \%)$ were around 15000-20000 rupees/month and 5(12.5\%) were above 20000 rupees of monthly income. Out of 40 samples 29(72.5\%) were from nuclear family and 11(27.5\%) were from joint family (Table 1).

According to personal habits $8(20 \%)$ having habit of smoking, $1(2.5 \%)$ has chewing tobacco and betel leaves, 6(15\%) were alcoholic and $25(62.5 \%)$ were having none of these habits. Distribution of samples with chronic disease $5(12.5 \%)$ having diabetes mellitus, hypertension for 4(10\%) samples, 3(7.5\%) having asthma and $28(70 \%)$ were not having such associated disease.

Out of 40 patients all of them $40(100 \%)$ had inadequate knowledge on post-operative exercises. (Table 2). And out of 40 patients one (2.5\%) had moderately adequate Knowledge, 39 (97.5\%) had adequate knowledge (Table-3). The pre-test mean for the samples was 4.55 with standard deviation 1.39 and in post-test samples mean was 18.00 with standard deviation 1.13. It shows that there is an increase in mean and standard deviation between pre-test and post-test (Table 4).

\section{Discussion}

The aim of the present study was to determine the effectiveness of video assisted teaching in knowledge and practice on post-operative exercises among abdominal surgery patients in selected hospitals at Kerala. Out of 40 patients in pretest knowledge level, all of 40 (100\%) had inadequate knowledge on post-operative exercises which was explained in table 2 . The previous studies reported that, 
awareness and knowledge regarding post-operative exercise is still inadequate among the abdomen surgery patients. The study was conducted with 100 samples were 50 for control group and 50 for experimental group. In that structured teaching was given for experimental group and the scores were compared for both groups, the paired ' $t$ ' test value for experimental group was $t=36.686$ which is highly significant at the level $\mathrm{P}=0.000$ and for control group was $\mathrm{t}=0.829$ which is not significant at the level $\mathrm{P}=0.411$.

There is no difference in measured pain during the preoperative and postoperative periods for either group, or after physiotherapy. These findings are at odds with the reasoning that mobilization may increase pain intensity after abdominal surgery Nonetheless; these same findings are in line with the notion that not only analgesic treatment but also physiotherapy for abdominal and thoracic surgery can reduce the hospital stay and improve recovery. [8]. There was no difference in measured pain during the preoperative and postoperative periods for either group, or after physiotherapy. Some patients in the chest physiotherapy group even reported some pain reduction after the exercises. These findings are at odds with the reasoning that mobilization may increase pain intensity after abdominal surgery [9]. The effects of different chest physiotherapy regimens have been evaluated among high-risk postoperative patients and none of them could be considered highly satisfactory with regard to preventing such complications. [10] Nonetheless, these same findings are in line with the notion that not only analgesic treatment but also physiotherapy for abdominal and thoracic surgery can reduce the hospital stay and improve recovery. [11]. the postoperative spirometry results presented in this study by the two groups did not show any significant differences. Spirometry as a means of quantifying lung function is controversial. Its best results may not be achieved after abdominal surgery, since patients are un-able to perform at their best or even to make a moderate effort to reach total pulmonary capacity or produce maximal forced expirations [12] Intraoperative, bronchospasm occurs most commonly during the induction and maintenance stages of anesthesia and is less often encountered in the emergence and recovery stages [13].

\section{Conclusion}

The pre-test knowledge had inadequate knowledge on post-operative exercises among abdominal surgery patients in tertiary care hospital in Kerala.

\section{References}

[1]. Beaussier M. Frequency, intensity, development and repercus-Frequency, intensity, development and repercussions of postoperative pain as a function of the type of surgery]. Ann Fr Anesth Reanim. 1998; 17(6):471-93.

[2]. Chumillas S, Ponce JL, Delgado F, Viciano V, Mateu M. Prevention of postoperative pulmonary complications through respiratory rehabilitation: a controlled clinical study. Arch Phys Med Rehabil.1998; 79(1):5-9.

[3]. Christensen EF, Schultz P, Jensen OV, et al. Postoperative pul-monary complications and lung function in high-risk patients: a comparison of three physiotherapy regimens after upper abdominal surger $\mathrm{y}$ in general anesthesia. Acta Anaesthesiol Scand. 1991; 35(2):97-104.

[4]. Chumillas S, Ponce JL, Delgado F, Viciano V, Mateu M. Prevention of postoperative pulmonary complications through respiratory rehabilitation: a controlled clinical study. Arch Phy+ s Med Rehabil. 1998; 79(1):5-9.

[5]. Hall JC, Tarala R, Harris J, Tapper J, Christiansen K. Incentive spirometry versus routine chest physiotherapy for prevention of pulmonary complications after abdominal surgery. Lancet. 1991; 337(8747):953-6.

[6]. Kassavin DS, Kuo YH, Ahmed N. Initial systolic blood pressure and ongoing internal bleeding following torso trauma. J Emerg Trauma Shock. 2011; 4(1):37-41.

[7]. Malcolm R. Calmer Moroney's Surgery for Nurses.16 ${ }^{\text {th }}$ Edition. 2002; Pp 1-25.

[8]. Nesbitt I. Postoperative monitoring. Curr Anaesth Crit Care. 2006; 17:55-64.

[9]. Paulo.et al. Chest Physiotherapy during immediate post-operative period among patients undergoing abdominal surgery. Sao Paulo Medical Journal. 2009

[10]. Ravindra P, Fitzgerald E. Surgical preoperative assessment: What to do and why. Student BMJ , 2012 (08)12;20 
DOI: $10.21522 / \mathrm{TIJBMS.2016.02.02.Art008}$

ISSN: $2519-500 \mathrm{X}$

[11]. Scottish Intercollegiate Guidelines Network (SIGN) Postoperative management in adults: a practical guide to postoperative care for clinical staff. SIGN publication [Internet] Available from: http://www.sign.ac.uk/ 2004.

[12]. Vimlati L, Gilsanz F, Goldik Z. Quality and safety guidelines of postanaesthesia care: Working Party on Post Anaesthesia Care (approved by the European Board and Section of Anaesthesiology, Union Europeenne des Medecins Specialistes) Eur J Anaesthesiol. 2009; 26 (9):715-21.

[13]. Westhorpe RN, Ludbrook GL, Helps SC. Crisis management during anaesthesia: Bronchospasm. Qual Saf Health Care. 2005; $14: 7$. 